\title{
Effect of Variability of Soil Parameters in the Behavior of Shallow Foundations
}

\author{
Tahar Messafer ${ }^{(\bowtie)}$ \\ Civil Engineering Department, University M'Hamed Bougara Boumerdes, \\ Boumerdès, Algeria \\ tmessafer@hotmail.co.uk
}

\begin{abstract}
This work is divided into two folds. The first stage was to carry out a statistical study of geotechnical soil parameters obtained for a housing project. This comprised analysis of the mean, standard deviation, coefficient of variance, histograms, cumulative densities and normal distribution laws. In addition correlation using linear regression analysis was carried out between pairs of soil parameters obtained from laboratory tests. Then autocorrelation functions were developed for pressuremeter modulus.

The second stage was to develop a probabilistic approach to design shallow foundations. This assumed that strengths parameters such as cohesion and angle of shearing strength are variable. The results were compared to traditional techniques based on Terzaghi methods such as DIN and DTU and also to semi probabilistic approach such as Eurocode.
\end{abstract}

Keywords: Statistical analysis - Correlation - Laboratory tests - In situ test Foundation analysis $\cdot$ Probabilistic approach

\section{Introduction}

The design of civil engineering structures requires a good knowledge of the subgrade. The first stage of a project is a geotechnical investigation as it allows the engineer to select representative values of soil characteristics necessary for the design. However, it is impossible to define in any point of a site the soil properties because the determination of representative parameter values is generally carried out on the basis of a few samples taken almost at random and in situ tests executed following a more or less wide mesh.

This is why the development of methods of statistical analysis and probability for the characterization of physical and mechanical properties of soils should solve the problem of variability of soil parameters. Then the use of these statistical methods in the probabilistic foundation design might be more advantageous compared to traditional methods used at present.

\section{Site Presentation}

The project is located in a mountainous region (Medea) in Algeria and includes the completion of 500 and 200 housing units as part of a 2000 housing program. The investigation in situ comprised the completion of 11 boreholes of $15 \mathrm{ml}, 6$ boreholes of $20 \mathrm{ml}$, 
5 pressuremeter tests of $10 \mathrm{ml}, 60$ dynamic penetration tests and 2 piezometers $20 \mathrm{ml}$ each deep.

Analysis of the results indicated the presence of two main layers which are:

Layer 1: silty clay with a thickness of about $4 \mathrm{~m}$

Layer 2: gray marl

\section{Statistical Analysis of Geotechnical Parameters}

Data analysis will focus on the results of laboratory and in situ tests for model one layer (Site) and model two layers (clay and marl). The results compare values of the min, max, average, standard deviation and coefficient of variance (CV) for the 2 models.

Several geotechnical parameters were analyzed such as the density, water content, degree of saturation, grading analysis, Atterberg limits, compressibility parameters, compression index, swelling coefficient, cohesion and angle of friction. As well as the results of pressuremeter tests.

Only limits results obtained for models one layer and two layers are provided on Table 1 and these show that the two layers are both plastic.

Table 1. Summary of models Atterberg limits single layer, two layers

\begin{tabular}{l|l|l|l|l|l|l|l}
\hline Paramètres & Model & $\begin{array}{l}\text { Nbre sampl } \\
\text { retained }\end{array}$ & $\begin{array}{l}\text { Min } \\
\text { values }\end{array}$ & $\begin{array}{l}\text { Max } \\
\text { values }\end{array}$ & $\begin{array}{l}\text { Average } \\
\text { values }\end{array}$ & $\begin{array}{l}\text { Stand } \\
\text { déviation }\end{array}$ & $\begin{array}{l}\text { CV } \\
(\%)\end{array}$ \\
\hline \multirow{2}{*}{ WL (\%) } & Site & 36 & 45 & 59 & 54,24 & 4,13 & 7,62 \\
\cline { 2 - 8 } & Clay & 26 & 46 & 59 & 54,08 & 4,21 & 7,79 \\
\cline { 2 - 8 } & Marl & 10 & 45 & 59 & 54,10 & 4,18 & 7,72 \\
\hline \multirow{3}{*}{ IP (\%) } & Site & 36 & 22 & 29 & 27,00 & 2,09 & 7,76 \\
\cline { 2 - 8 } & Clay & 26 & 23 & 29 & 26,96 & 2,16 & 8,02 \\
\cline { 2 - 8 } & Marl & 10 & 22 & 29 & 25.50 & 2,11 & 8.27 \\
\hline
\end{tabular}

\section{Analysis of Variability}

Histograms and cumulative distribution of geotechnical parameters have been developed. Results for plasticity index (Ip) are shown on Fig. 1. A graphical representation of classes is given in histograms shown in Fig. 2.

From the results it can be seen that the Ip histogram for clay is identical to the site histogram. Hence to calculate the frequency or density of the site, clay data can be taken. Adopting Fig. 1, the cumulative distribution of Ip is shown in Fig. 3. 


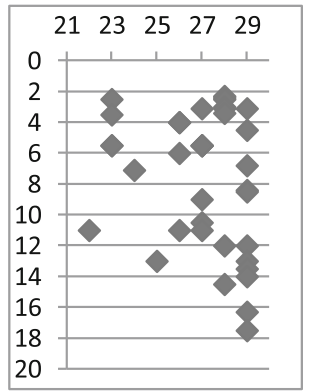

a) Site

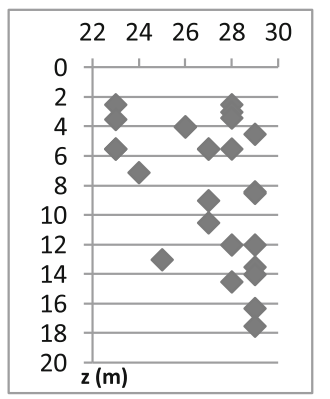

b) Clay

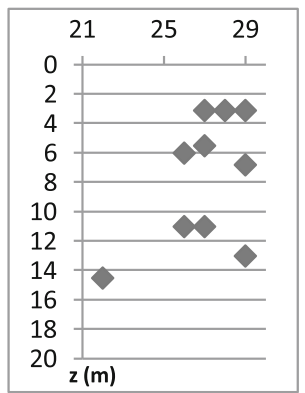

c) Marl

Fig. 1. Distribution de Ip with depth for model 1(a) and model 2(b and c)

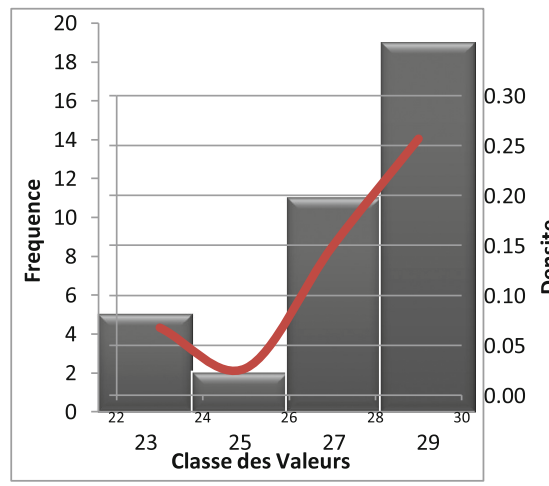

.a. Site

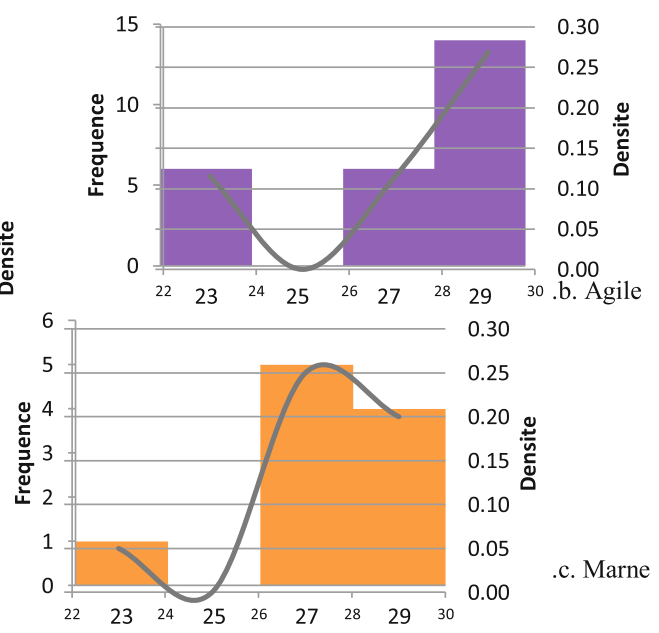

Fig. 2. Histograms of Ip

Figures 4, 5 and 6 show Gauss normal laws $\mathrm{f}(\mathrm{z})$ and the corresponding probabilities for Ip for the whole site and layers of Clay and Marl respectively. 


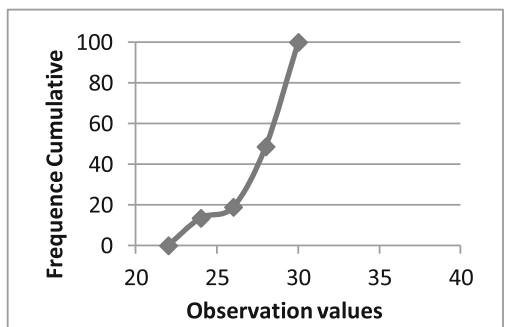

a) Site

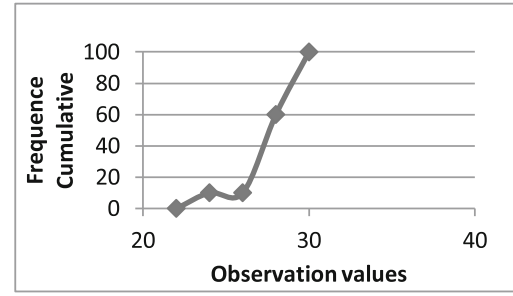

c) Marl

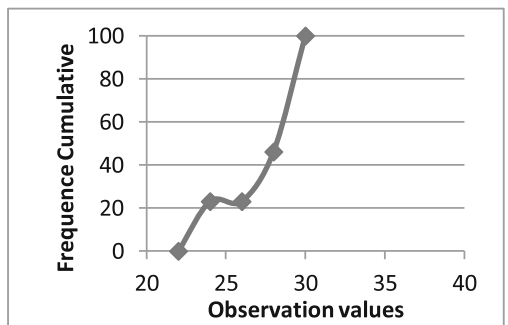

b) Clay

Fig. 3. Cumulative distribution of Ip

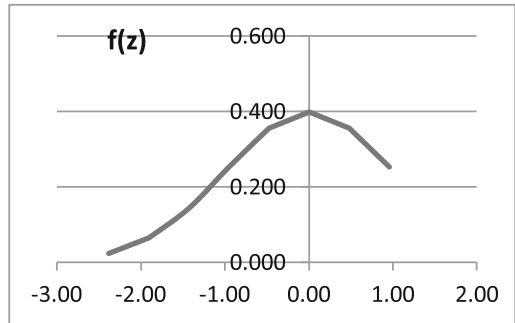

(a) Fonction de $\mathrm{f}(\mathrm{z})$

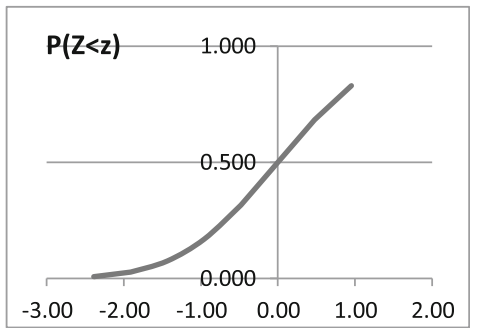

(b) Probabilité

Fig. 4. Normal distribution de Ip pour le Site
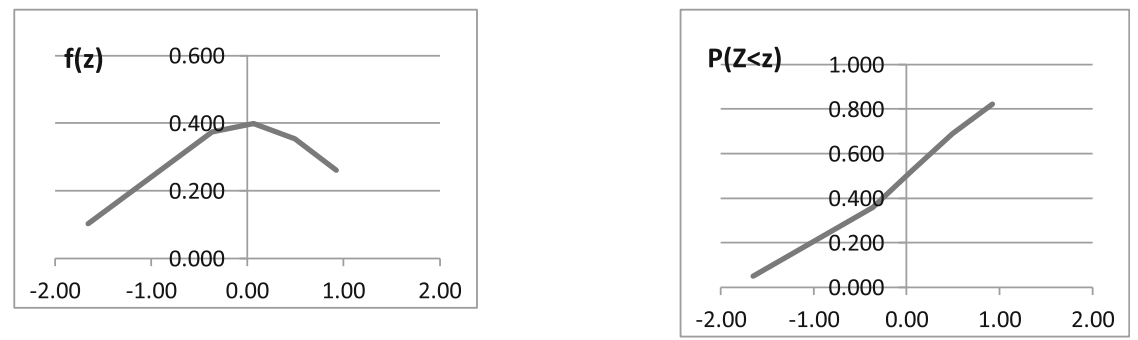

Fig. 5. Normal distribution of Ip for clay 


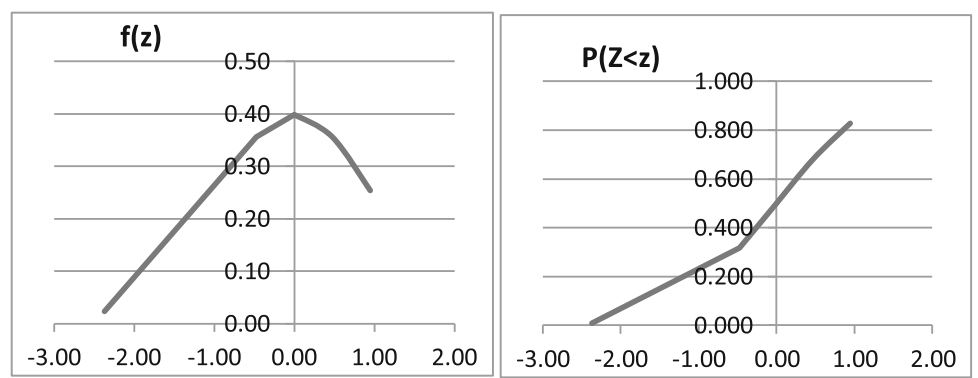

Fig. 6. Normal distribution of Marl

\section{Correlations and Lineair Regressions}

Figure 7 shows results of water content and Atterberg Limits correlations. The result gave good correlations between WL and IP for the whole site, clay and marl layers reflecting similarity of site materials origins. These results are similar to correlations obtained by several authors, for example by Magnan [1]: $\mathrm{WL}=1.04 \mathrm{Ip}+27.02 \mathrm{R}=0.90$
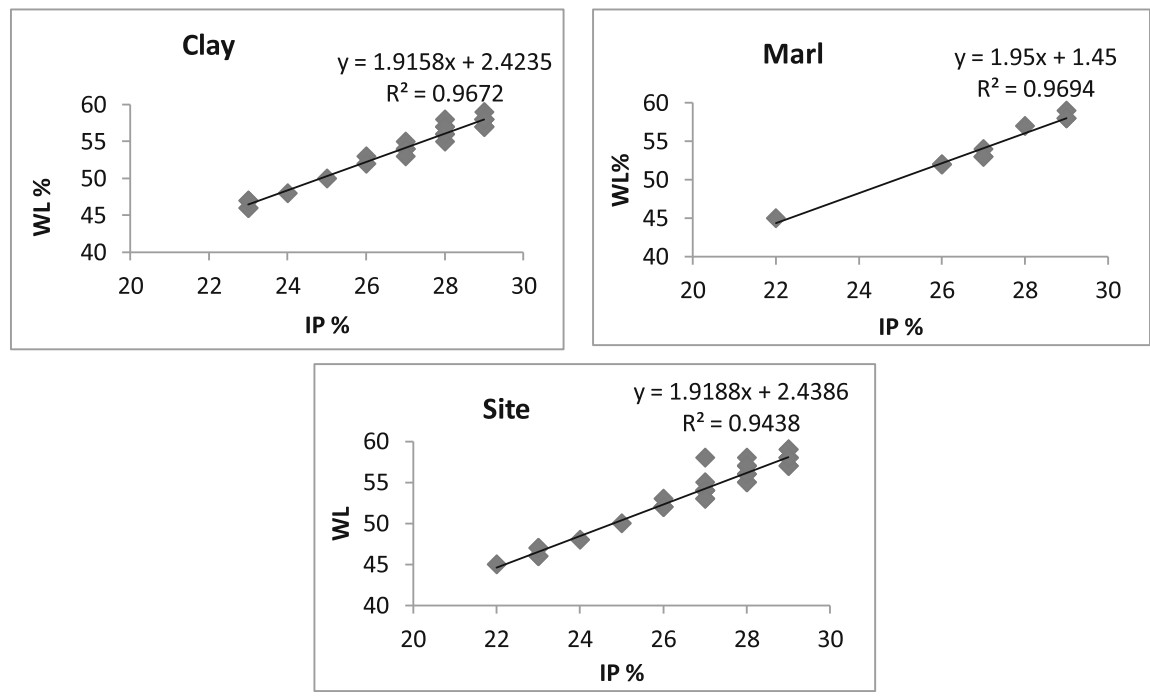

Fig. 7. Relations between water content and Atterberg limits

\section{Spatial Auto-correlation}

Analysis of spatial variability of physical and mechanical properties of the site was performed for the pressuremeter survey. The analysis was carried out in the vertical direction as it contained enough regularly spaced data. The purpose of this analysis is to determine the auto-correlation function which describes the representation given in the 
vertical direction and also to determine the remote auto correlation (or fluctuation scale) which determines the degree of dispersion of data.

The auto-correlation is a measure of the dependence of two or more points in a data set. From measurements $y_{i}$ given $x_{i}$ equidistant from a property, the estimated value of the auto-correlation between two values distant by x can be defined as follows, Salloum [2]:

$$
\rho_{\tau}=\frac{\sum_{i=1}^{n-\tau}\left(y_{i}-\bar{y}_{i}\right)\left(y_{i+\tau}-\bar{y}_{i+\tau}\right)}{\sum_{i=1}^{n}\left(y_{i}-\bar{y}_{i}\right)^{2}} \tau=0,1,2, \ldots, n-1
$$

Where $\mathrm{n}$ is the number of measurements of the soil property and $\tau$ is the shift of the data set. $\bar{y}_{i}$ and $\bar{y}_{i+\tau}$ are values of the measured trends at $x_{i}$ and $x_{i+\tau}$ respectively.

Among the auto-correlation function models, exponential functions of the following form: $C . e^{-\frac{|\tau|}{a}}$ can be used (Imanzadeh [3]):

$\tau$ represents the distance between two points of the ground where it is desired to determine the correlation and $\mathrm{a}$ is the auto correlation distance.

A simple but approximate method for calculating the vertical scale of fluctuation is given by Vanmarcke [4] as follows:

$$
\delta_{v} \approx 0.8 \bar{d} \quad \text { with } \quad \bar{d}=\frac{1}{n-1} \sum_{i=1}^{n-1} d_{i}
$$

Where $\delta_{v}$ is the vertical fluctuation scale and $\bar{d}$ is the average value of distances limited by the intersections of the trend function with the function $\xi(\mathrm{z})$ of soil property.

\subsection{Drift Average Values (Linear Regression)}

Observation of measured values distributions of soil parameters as a function of depth leads to visually distinguish two layers: a $4 \mathrm{~m}$ thick followed by a layer of $6 \mathrm{~m}$ as shown in Fig. 8. This represents measured values of pressuremeter module (EM) in a pressuremeter test.
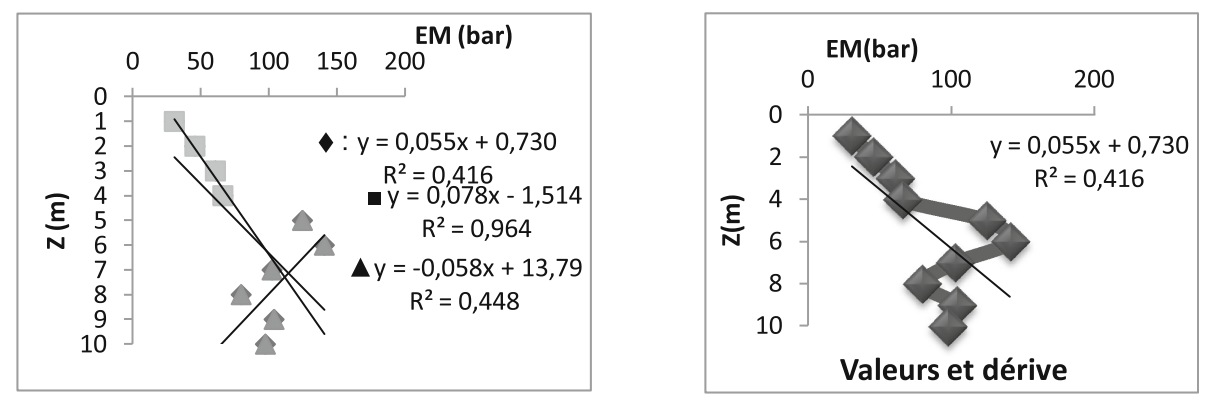

Fig. 8. Spatial variability of pressuremeter module (EM) 

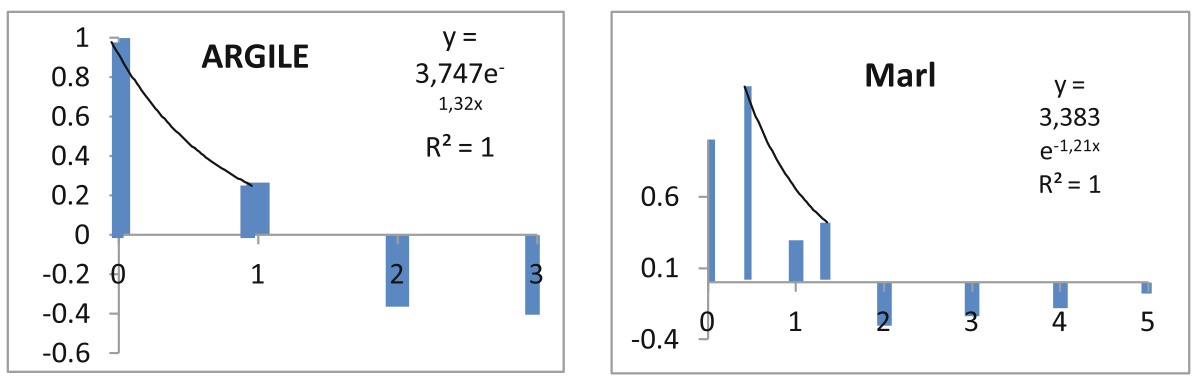

Fig. 9. Autocorrelation diagrams and EM autocorrelation functions in clay and marl

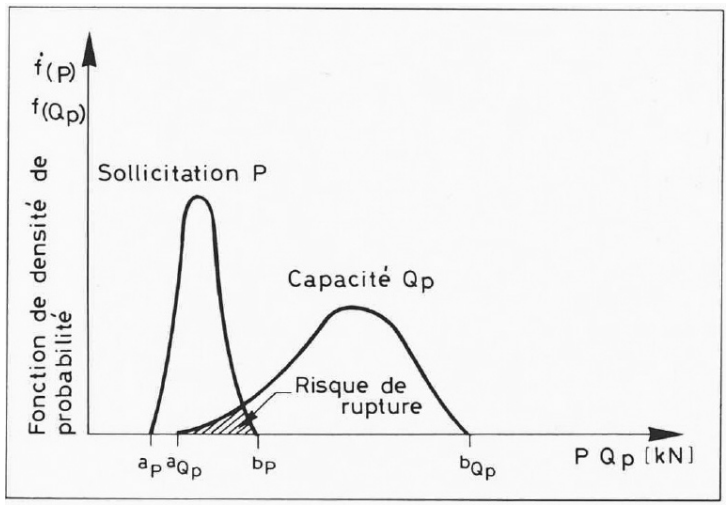

Fig. 10. Capacity-Solicitation model

\subsection{Functions and Auto-correlation Distances}

Figures 9 and 10 show the auto-correlation charts and autocorrelation functions of EM in the vertical direction for each layer separately (Marl and clay) and for the whole site.

For each auto-correlation diagram, an exponential function of the form, $y=C \cdot e^{-\frac{|x|}{a}}$, has been adjusted on the first three or four values of the coefficient of auto-correlation, distance of auto correlation and fluctuation scale $\theta=2 \mathrm{a}$.

Table 2 shows the results of the function of autocorrelation adjusted for pressuremeter modulus data in the clay and the marl.

The auto-correlation function in the vertical direction of EM was determined for clay and marl. The best results were obtained with the exponential function (Figs. 9 and 10) for which the value of $\mathrm{R}^{2}$ is the highest.

The $\mathrm{R}^{2}$ value obtained was found greater than 0.903 , and the vertical autocorrelation distance was found around $0.52 \mathrm{~m}$ in clay and $0.59 \mathrm{~m}$ in the marl. This means that the pressuremeter modulus vary in the clay layer in an identical manner to the marl. 
Table 2. Autocorrelation function, fluctuation scale $\theta$ wide field and the coefficient of determination $\mathrm{R}^{2}$ in clay and marl and the whole site

\begin{tabular}{l|l|l|l|l|l}
\hline Paraméter & $\begin{array}{l}\text { Nature } \\
\text { of soil }\end{array}$ & $\begin{array}{l}\text { Auto-corrélation } \\
\text { function } \rho(\tau)\end{array}$ & $\begin{array}{l}\text { Auto-corrélation } \\
\text { distance a }\end{array}$ & $\begin{array}{l}\text { Fluctuation } \\
\text { scale } \theta\end{array}$ & $\mathrm{R}^{2}$ \\
\hline \multirow{2}{*}{ EM } & Clay & $\mathrm{y}=3,747 \mathrm{e}^{-1,32 \mathrm{x}}$ & 0.266 & 0.52 & 1 \\
\cline { 2 - 6 } & Marl & $\mathrm{y}=3,383 \mathrm{e}^{-1,21 \mathrm{x}}$ & 0.295 & 0.59 & 1 \\
\cline { 2 - 6 } & Site & $\mathrm{y}=5,188 \mathrm{e}^{-1,38 \mathrm{x}}$ & $0.72 \mathrm{~m}$ & $1.44 \mathrm{~m}$ & 0,903 \\
\hline
\end{tabular}

The vertical distance of autocorrelation obtained for EM varies between 0.5 and 1.44. This indicates that these values are not dispersed.

\section{Fondation Calculation}

A probabilistic approach enables the study of the risk of failure by taking into account the variability of geotechnical parameters and also the variability of the pressure acting on the foundations. In what follows, traditional calculation results (Terzaghi, DTU, DIN) and Eurocode will be compared to probabilistic results, considering a normal distribution law.

\subsection{Calculation of Bearing Capacity from Laboratory Tests}

In the case of a strip footing, the bearing capacity under a vertical centered load is given by the following general relation (superposition method of Terzaghi):

$$
q_{l}=\frac{1}{2} \gamma_{1} B N_{\gamma}(\varphi)+c N_{c}(\varphi)+\left(q+\gamma_{2} D\right) N_{q}(\varphi)
$$

With:

$q_{l}$ and q: bearing capacity and vertical lateral pressure respectively

$\gamma_{1}, \gamma_{2}$ : Volumetric weight of the soil under the base of the foundation and laterally respectively

c: Cohesion of soil under the base of the foundation

B and D: Width of the foundation and ancrage depth of the foundation, respectively $N_{\gamma}(\varphi), N_{c}(\varphi)$ and $N_{q}(\varphi)$ : Bearing Factors of the foundation

Table 3 contains the formulas of these three factors according to the French, German and Eurocode conventional concepts.

Table 3. Bearing capacity factors

\begin{tabular}{l|l|l|l}
\hline \multirow{2}{*}{ Concept } & \multicolumn{2}{|l}{ Bearing factors } \\
\cline { 2 - 4 } & $N_{\gamma}$ & $N_{c}$ & $N_{q}$ \\
\hline $\begin{array}{l}\text { Conventionnel French } \\
\text { (DTU13.12) }\end{array}$ & $1,85(N q-1) \tan \varphi$ & $\left(N_{q}-1\right) \cot \varphi$ & $e^{\pi \tan \varphi} \cdot \tan ^{2}\left(\frac{\pi}{4}+\frac{\varphi}{2}\right)$ \\
\hline Conventionnel German & $2(N q-1) \tan \varphi$ & & \\
\hline Eurocode 7-1 & $2(N q-1) \tan \varphi$ & & \\
\hline
\end{tabular}




\subsection{Allowable Bearing Capacity of a Foundation (According to Terzaghi)}

$$
q_{a}=\gamma_{1} \cdot D+\frac{q_{l}-\gamma_{1} \cdot D}{F}
$$

\subsection{French Conventional Concept (DTU13.12)}

$$
q_{\text {réel }} \leq q_{a d}
$$

$q_{\text {réel }}, q_{a d}$ : real stress applied to the foundation and allowable pressure respectively

$$
q_{a d}=\gamma D+\frac{\gamma \frac{B}{2} N_{\gamma}+\gamma D\left(N_{q}-1\right)+c N_{c}}{F_{s}}
$$

\subsection{Conventional German Concept DIN 1054}

$$
\frac{V_{b}}{V} \geq F s \quad \text { With } \quad V_{b}=q_{L} \cdot A
$$

A: area of the foundation and Fs: global safety factor

$V_{b}$ and $\mathrm{V}$ : Limit load and external load applied on the foundation

\subsection{Eurocode 7.1 (Semi-probabilistic Calculation for Safety)}

Partial safety factors are applied to the soil parameters $(\gamma, \mathrm{c}, \varphi)$. The bearing capacity calculation is calculated as follows:

$$
R_{d}=Q_{L}\left(\varphi_{d}^{\prime}, c_{d}^{\prime}, \gamma_{d}\right)
$$

With, $c_{d}^{\prime}=\frac{c_{k}^{\prime}}{\gamma_{c^{\prime}}} \quad, \quad \tan \varphi_{d}^{\prime}=\frac{\tan \varphi_{k}^{\prime}}{\gamma_{\varphi^{\prime}}} \quad \gamma_{d}=\gamma_{k}$

The variation of $\gamma$ specific weight is very low, for this reason we take $\gamma=1$.

$\gamma_{\varphi^{\prime}}, \gamma_{c^{\prime}}$ : Partial safety factors applied to $\varphi^{\prime}$ and $c^{\prime}$ respectively

Indices $\mathrm{k}$ and $\mathrm{d}$ mean characteristic value and design value respectively

\subsection{Probabilistic Method}

The few published work on this subject (Mounji et al. [5], Chew et al. [6]) has shown the importance of taking account of soil variability. In this work, the capacity $(\mathrm{Q})$ and solicitation (S) are considered random variables each having a mean and standard deviation.

The difference between the two random variables $(\mathrm{Z}=\mathrm{Q}-\mathrm{S})$ is called margin of safety and is also a random variable. A limit state is reached when $Z=0$ and failure occurs when $\mathrm{Z}<0$, and the probability of failure can be defined as (Boutahir et al. [7]): 


$$
P_{f}=P_{f}[(Q-S) \leq 0]=P_{f}(Q \leq S)
$$

Where R and S follow Gauss normal distributions, the safety margin (Z) also follows a normal distribution.

$$
f(Z)=\frac{1}{s_{z} \sqrt{2 \pi}} \cdot e^{-\left(Z-\mu_{Z}\right)^{2} / 2 s_{z}^{2}}
$$

Whose mean and standard deviation are respectively:

$$
\mu_{Z}=\mu_{R}-\mu_{S} \quad \text { and } \quad s_{z}=\sqrt{s_{R}^{2}-s_{S}^{2}}
$$

The hatched area of Fig. 10 being the failure probability $\mathrm{P}_{\mathrm{f}}$ calculated with the integral:

$$
P_{f}=\int_{-\infty}^{0} f_{Z}(Z) \cdot d Z
$$

Bearing capacity $q_{l}$, based on random variables $\varphi, c$ and $\gamma$

The function $q_{l}(\varphi, \gamma, \mathrm{c})$ can be developed into a Taylor series. If we take the terms of the lowest order non null, we can calculate the mathematical expectation $\bar{y}$ and the variance $S_{y}^{2}$ of a function $\mathrm{y}=f\left(x_{1}, x_{2} \ldots x_{n}\right)$, (Hahn and Shapiro [8]), with $x_{i}$ random variables defined by their average $\mu_{i}$ and their variance $S_{i}^{2}$ :

$$
\begin{gathered}
\bar{y}=f\left(\mu_{1}, \mu_{2}, \ldots, \mu_{n}\right)+\frac{1}{2} \sum_{i=1}^{n} \frac{\delta^{2} f}{\delta_{x_{i}}^{2}}\left(S_{i}^{2}\right) \\
S_{y}^{2}=\sum_{i=1}^{n}\left(\frac{\delta f}{\delta x_{i}}\right)^{2}\left(S_{i}^{2}\right)
\end{gathered}
$$

The coefficient of variation of $y$ will be:

$$
V_{y}=\frac{S_{y}}{\bar{y}}
$$

In the case of $q_{P}(\varphi, \gamma$ and $c)$, expressions (12) and (13) become:

$$
\begin{gathered}
\mu_{q}=\bar{q}_{p}=c N_{c} \lambda_{c}+\gamma t N_{q} \lambda_{q}+\gamma \frac{B}{2} N_{\gamma} \lambda_{\gamma} \frac{1}{2}\left(c \lambda_{c} \frac{\delta^{2 N_{c}}}{\delta \varphi^{2}}+\gamma t \lambda_{q} \frac{\delta^{2 N_{q}}}{\delta \varphi^{2}}+\gamma \frac{B}{2} \frac{\delta^{2 N_{\gamma}}}{\delta \varphi^{2}} \lambda_{\gamma}\right) S_{\varphi}^{2} \\
S_{q}^{2}=\left(c \lambda_{c} \frac{\delta N_{c}}{\delta \varphi}+\gamma t \lambda_{q} \frac{\delta N_{q}}{\delta \varphi}+\gamma \lambda_{\gamma} \frac{B}{2} \frac{\delta N_{\gamma}}{\delta \varphi}\right)^{2} S_{\varphi}^{2}+N_{c}^{2} \lambda_{c}^{2} S_{c}^{2}+\left(t N_{q} \lambda_{q}+\frac{B}{2} N_{\gamma} \lambda_{\gamma}\right)^{2} S_{\gamma}^{2}
\end{gathered}
$$




\subsection{Calculation Results}

\subsubsection{Traditional Method}

The geotechnical investigation conducted on the site helped fix a founding level of $2 \mathrm{~m}$ depth below ground level. Widths calculations at this depth for a strip footing and for $\gamma 1=\gamma 2=20 \mathrm{kN} / \mathrm{m} 3$ and solicitation $\mathrm{S}=300 \mathrm{kN} / \mathrm{ml}$ are shown in Table 4 .

Table 4. Widths B with Terzaghi method for Fs $=2$ and 3

\begin{tabular}{l|l|l|l|l|l|l|l|l|l}
\hline$\varphi^{\prime}\left[^{\circ}\right] / \mathrm{c}^{\prime}[\mathrm{kPa}]$ & $13 / 40$ & $15 / 61$ & $15 / 49$ & $14 / 51$ & $15 / 44$ & $15 / 53$ & $16 / 53$ & $14 / 58$ & $15 / 51$ \\
\hline Fs $=2$ & 1,09 & 0,7 & 0,83 & 0,86 & 0,90 & 0,79 & 0,73 & 0,78 & 0,81 \\
\hline Fs $=3$ & 1,60 & 1,04 & 1,23 & 1,27 & 1,32 & 1,17 & 1,09 & 1,16 & 1,20 \\
\hline
\end{tabular}

\subsubsection{DTU, DIN and Eurocode Methods}

The results are given on Table 5 .

Table 5. Widths B for DTU, DIN and Eurocode 7.1 methods

\begin{tabular}{l|l|l|l|l|l}
\hline$\varphi^{\prime}\left[{ }^{\circ}\right] / \mathrm{c}^{\prime}[\mathrm{kPa}]$ & \multicolumn{2}{l|}{ DIN 1054} & \multicolumn{2}{l|}{ DTU 13.12} & \multirow{2}{*}{ Eurocode 7 } \\
\cline { 2 - 5 } & Fs =2 & Fs = 3 & Fs = & Fs = 3 & \\
\hline $13 / 40$ & 1,09 & 1,60 & 1,01 & 1,40 & 1,58 \\
\hline $15 / 49$ & 0,83 & 1,23 & 0,79 & 1,11 & 1,21 \\
\hline $15 / 44$ & 0,90 & 1,32 & 0,85 & 1,18 & 1,30 \\
\hline $16 / 53$ & 0,73 & 1,09 & 0,70 & 0,99 & 1,07 \\
\hline $15 / 51$ & 0,81 & 1,20 & 0,77 & 1,09 & 1,18 \\
\hline
\end{tabular}

The results show that the widths obtained from DIN approach are slightly higher than those of the DTU. However the results of Eurocode are much closer to the results of $\mathrm{DIN}$ for $\mathrm{FS}=3$.

\subsubsection{Probabilistic Method}

The foundation is a strip footing width of B and parameters shown on Table 6.

Table 6. Mechanical properties of the soil

\begin{tabular}{l|l|l|l|l|l|l|l|l|l|l|l|l|l|l}
\hline \multicolumn{10}{l|}{} \\
\hline$\varphi^{\prime}$ & $\left(^{\circ}\right)$ & 13 & 15 & 15 & 14 & 15 & 15 & 16 & 14 & 15 & 15 & 0,87 & 0,06 & 0,75 \\
\hline$\gamma_{1}$ & kN.m-3 & 20,9 & 20,9 & 20,6 & 20,8 & 20,6 & 20,1 & 20,6 & 20,5 & 20,0 & 20,6 & 0,32 & 0,02 & 0,10 \\
\hline$c^{\prime}$ & kN.m-2 & 40 & 61 & 49 & 51 & 44 & 53 & 53 & 58 & 51 & 51,1 & 6,43 & 0,13 & 41,36 \\
\hline
\end{tabular}

It is considered that the solicitation (S) and the capacity $(\mathrm{Q})$ are random and follow a normal probability law and thus the safety margin $(\mathrm{Z}=\mathrm{Q}-\mathrm{S})$ also follows a normal distribution.

The results of long-term load bearing capacities are summarized on Table 7.

Values $\mu_{q}$ and $s_{q}$ used for the calculation of risk are determined from Table 8. 
Table 7. Probability of a value being smaller than $\mathrm{z}$ for a standard normal distribution

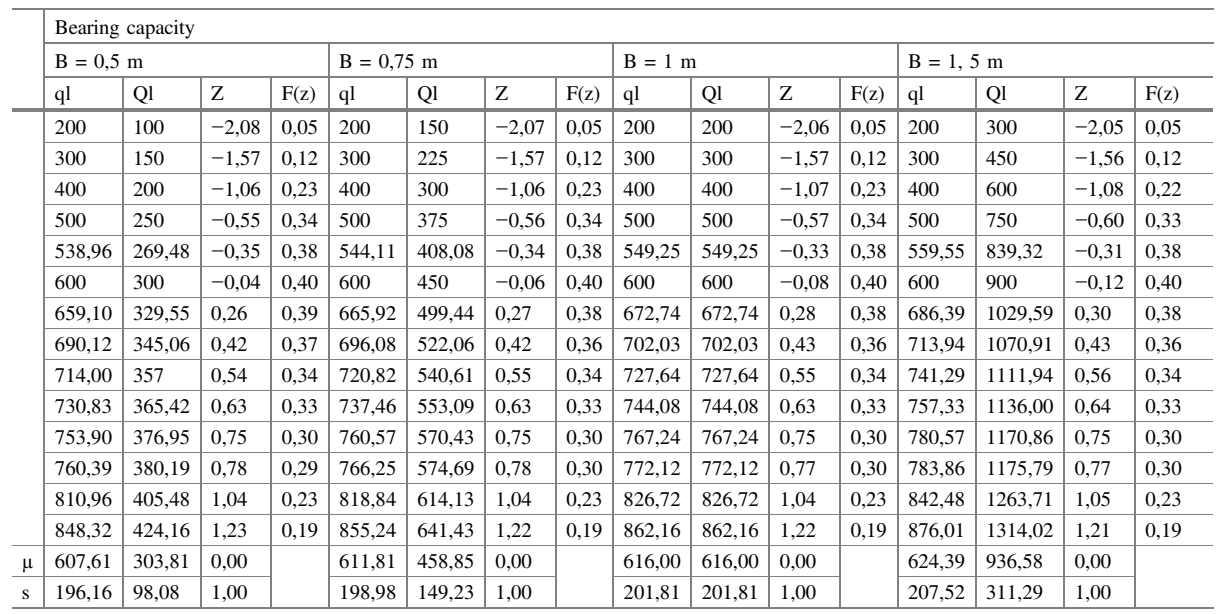

Table 8. Calculation of $\mu_{q}$ et de $s_{q}$ for différent B

\begin{tabular}{l|l|l|l|l}
\hline \multirow{2}{*}{ Sol } & \multicolumn{4}{l}{ Clay } \\
\cline { 2 - 5 } & $\mathrm{B}=0,5 \mathrm{~m}$ & $\mathrm{~B}=0,75 \mathrm{~m}$ & $\mathrm{~B}=1 \mathrm{~m}$ & $\mathrm{~B}=1,5 \mathrm{~m}$ \\
\hline$c N c$ & 658,6 & 658,6 & 658,6 & 658,6 \\
\hline$\gamma t N q$ & 91,4 & 91,4 & 91,4 & 91,4 \\
\hline$\gamma B / 2 N \gamma$ & 15,0 & 22,5 & 30,0 & 45,0 \\
\hline$q_{l}$ & 765,1 & 772,6 & 780,1 & 795,1 \\
\hline $1 / 2 c d^{2} N c / d \varphi^{2} s_{\varphi}^{2}$ & 3867,8 & 3867,8 & 3867,8 & 3867,8 \\
\hline $1 / 2 \gamma t d^{2} N q / d \varphi^{2} s_{\varphi}^{2}$ & 1216,5 & 1216,5 & 1216,5 & 1216,5 \\
\hline $1 / 2 \gamma B / 2 d^{2} N \gamma / d \varphi^{2} s_{\varphi}^{2}$ & 561,9 & 842,9 & 1123,9 & 1685,8 \\
\hline Somme & 5646,3 & 5927,2 & 6208,2 & 6770,1 \\
\hline moyenne $\mu_{q}(\mathrm{kPa})$ & 6411,3 & 6699,8 & 6988,3 & 7565,2 \\
\hline$c d N c / d \varphi$ & 2294,4 & 2294,4 & 2294,4 & 2294,4 \\
\hline$\gamma t d N q / d \varphi$ & 530,9 & 530,9 & 530,9 & 530,9 \\
\hline$\gamma B / 2 d N \gamma / d \varphi$ & 131,2 & 196,8 & 262,3 & 393,5 \\
\hline Somme & 2956,5 & 3022,1 & 3087,7 & 3218,8 \\
\hline$(. . \text { somme.. })^{2} s_{\varphi}^{2}$ & 6555589,07 & 6849668,34 & 7150199,79 & 7770619,2 \\
\hline$N c^{2} s_{c}^{2}$ & 6867,97 & 6867,97 & 6867,97 & 6867,97 \\
\hline$(t N q+B / 2 N \gamma)^{2} s_{\gamma}^{2}$ & 2,67 & 3,056 & 3,47 & 4,38 \\
\hline$s_{q}^{2}$ & 6562459,70 & 6856539,37 & 7157071,23 & 7777491,55 \\
\hline Ecart type $s_{q}$ & 2561,73 & 2618,5 & 2675,27 & 2788,81 \\
\hline variance $V_{q}$ & 0,4 & 0,39 & 0,38 & 0,37 \\
\hline & & & & \\
\hline & & & & \\
\hline & & & &
\end{tabular}


First Case: Assume that the load is constant of intensity $\mathrm{S}=300 \mathrm{kN} / \mathrm{m}$, the probability of failure for widths $B$ of $0.5 \mathrm{~m} ; 0.75 \mathrm{~m} ; 1.0 \mathrm{~m}$ and $1.5 \mathrm{~m}$ are summarized on Table 9. Figure 11 shows the method of calculating the probability of failure for a width equal to $\mathrm{B}$ of $1 \mathrm{~m}$.

Table 9. Risk of failure for constant loads

\begin{tabular}{l|l|l|l|l}
\hline Widths B (m) & 0,5 & 0,75 & 1,0 & 1,5 \\
\hline Risk of failure (\%) & 59,3 & 29,8 & 18,2 & 10,1 \\
\hline
\end{tabular}

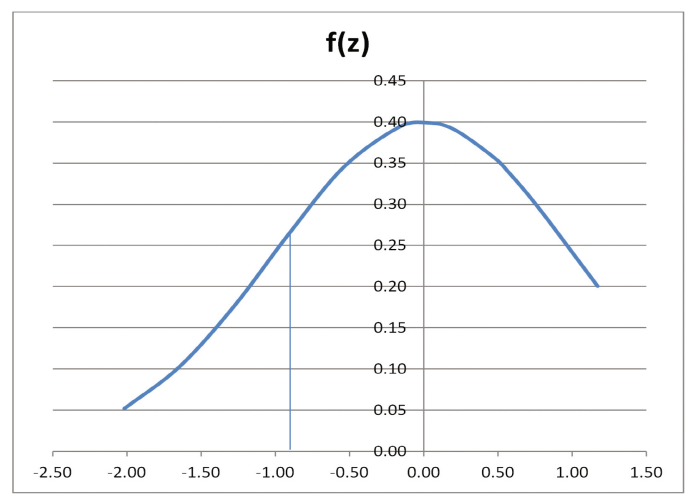

Fig. 11. Risk of failure for $B=1 \mathrm{~m}$

Second case: We assume that the stress (S) and the capacity (Q) are random with a normal distribution, the load to be transmitted to the ground is characterized by the following values.

Table 10. Risk of failure for variable loads and capacities

\begin{tabular}{l|l|l|l|l}
\hline Widths B (m) & 0,5 & 0,75 & 1,0 & 1,5 \\
\hline Probability de failure (\%) & 1,4 & 0,9 & 0,7 & 0,5 \\
\hline
\end{tabular}

Results for probability of risk calculation are shown in Table 10 for different widths B. Figure 12 shows the distributions of $\mathrm{Q}$ and $\mathrm{S}$ in the case where the width $\mathrm{B}$ is $1 \mathrm{~m}$.

$$
P_{f}=1-F\left(\frac{\mu_{S}-\mu_{Q}}{\sqrt{s_{S}^{2}+s_{Q}^{2}}}\right)=1-F(+2,46)=0,69 \%
$$




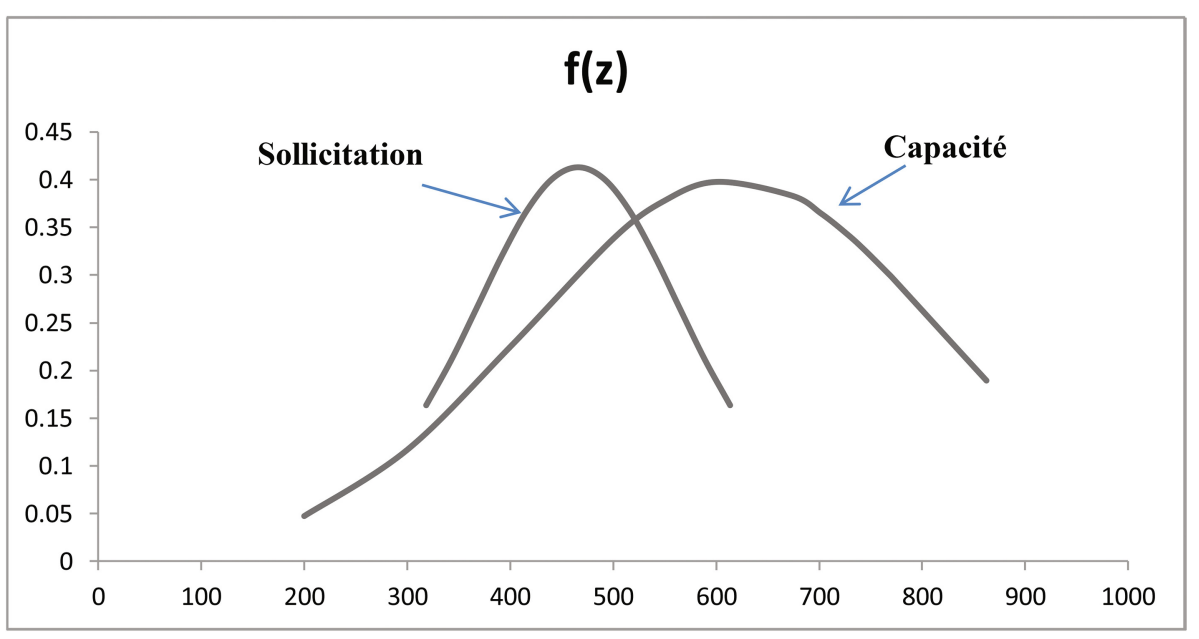

Fig. 12. Diagram of normal distribution of capacity and solicitation for $B=1 \mathrm{~m}$

The results show that the risk of failure in the case of a variable load is negligible for widths ranging between 0.5 to $1.5 \mathrm{~m}$. However in the case of a constant load, probability of failure varies from $60(\%)$ in the case of a $0.5 \mathrm{~m}$ width of foundation to $10(\%)$ in the case of a width of $1.5 \mathrm{~m}$. In general for widths larger than $1 \mathrm{~m}$ the probability of failure is less than $20(\%)$. With traditional methods (Terzaghi, DIN and DTU) to obtain B values between 1 and $1.5 \mathrm{~m}$, an Fs equal to 3 is required.

\section{General Conclusions}

The geotechnical investigation showed that the soil is composed of two essential layers namely a clay layer with thickness of $4 \mathrm{~m}$ followed by a layer of marl. In order to compare the results we decompose the soil in 2 models. The first model is the whole site as one layer (site) and the 2 nd is a two-layer soil (clay and marl).

The results of the geotechnical parameters were presented in the form of histograms, cumulative distributions and normal laws. Regression equations were established between pairs of parameters and gave results comparable to those in the literature.

We presented an analysis of the spatial variability of the pressuremeter modulus EM. We found that if we assume that EM is an exponential function, the autocorrelation distance is approximately $0.5 \mathrm{~m}$ indicating that EM values are not dispersed.

Foundation calculations were carried out by traditional probabilistic methods. We showed that in the probabilistic approach bearing capacity is a random parameter because it is based on parameters $\mathrm{c}$ and $\varphi$ which are themselves random. Compared to traditional methods the probabilistic approach is a powerful calculation tool but requires to be utilized among practitioners. 


\section{References}

1. Magnan, J.P, Baki. A., Pouget, P.: Analyse statistique de la variabilité des propriétés physiques et mécaniques d'un sol, Bulletin de liaison Laboratoire Centrale des Ponts et Chausse, No. 186 (1993)

2. Salloum, N.: Evaluation de la variabilité spatiale des paramètres géotechniques du sol à partir de mesures géophysiques: application à la plaine alluviale de Nahr-Beyrouth (Liban), Thèse de doctorat, Université de Grenoble, Liban (2015)

3. Imanzadeh, S.: Effects of uncertainties and spatial variation of soil and structure properties on geotechnical design. Cases of continuous spread footings and buried pipes, these de Doctorat, Université de Bordeaux, France (2013)

4. Vanmarcke, E.H.: Probabilistic modeling of soil profiles, America, society of civil engineers. J. Geotech. Eng. Div. 103(11), 1227-1246 (1977)

5. Mounji, M., Lahmili, A., Ouadif, L., Baba, K., Bahi, L.: Probabilistic approach for the selection of the shallow foundation's safety factor. Int. J. Eng. Technol. (IJET) 8(2), 7 (2016)

6. Chew, Y.M., NG, K.S., NG, S.F.: The effect of soil variability on the ultimate bearing capacity of shallow foundation. J. Eng. Sci. Technol., 1-13 (2015). Special issue on ACEE 2015 Conference

7. Boutahir, M., Belabed, L., Benyaghia, H.: Analyse fiabiliste de la capacité portante des fondations superficielles, Séminaire International, innovation et valorisation en génie civil et materiaux de construction, No 5P-092, Rabat, Maroc (2011)

8. Hahn, G.J., Shapiro, S.S.: Statistical models in engineering. Wiley Interscience Publisher (1994) 